\title{
An Analysis of Equity Among Policy Solutions for Traffic Congestion
}

\author{
Ethan Steakley
}

\begin{abstract}
he emergence of ride-hailing in the United States has brought forth new issues for its cities, particularly a large influx of traffic congestion. Today, several cities have introduced distinct ideas to solve congestion issues while debating their implications for equity. This paper examines the equity implications of traffic congestion in America's cities by comparing a flat tax rate on ride-hailing to various road pricing mechanisms using specific evaluative criteria, including transportation access and vertical equity. This paper begins with an overview of ride-hailing in the United States and the congestion problem it poses for cities, then reviews the literature around congestion and equity, describes and assesses the equity of a flat tax rate and road pricing, and ends with broad implications resourced from the literature for future policy.
\end{abstract}




\section{INTRODUCTION}

The emergence of ride-hailing companies, such as Uber and Lyft, introduced a mounting congestion problem, particularly for America's cities (Schaller 2018). This sparked heavy debate on how the industry should be regulated and how congestion strategies should be implemented (Suzor, Wikstrom, \& Witt 2015). One of the foremost concerns is that any action taken should be done with equity in mind. In a broad sense, equity is concerned with total cost and benefit directed toward different groups in society. The literature outlines several specific indicators that can be used to evaluate equity in congestion pricing methods (Maruyama \& Sumalee 2007). This paper will use the following two criteria sourced from the literature to assess the equity of a flat tax rate and road pricing mechanisms including area-based charging systems and service tolls: 1 . transportation access and 2 . vertical equity.

Transportation access refers to the extent to which a transportation system serves its purpose and provides equitable access to a variety of opportunities. Transportation accessibility indicators generally measure how easy it is to reach a destination from a location in a certain time frame or for a given cost. Therefore, accessibility increases as the distance and time to arrive at individual destinations decreases or the number of nearby destinations increases. Relying on transportation access allows us to uncover "linkages between transportation and land use that common mobility measures such as highway LOS [level of service] do not and it shifts the focus of equity analyses from outputs (e.g., spending) to actual outcomes" (McCahill and Ebeling 2015, 1).

Vertical equity looks at how outcomes differ between members of different groups, such as low-income vs high-income. This measure is satisfied by progressive/proportional taxes or those that are "levied on households proportional to the ability to pay." For example, income tax improves vertical equity by taxing according to how much people earn. In essence, the tax burden is spread proportionally where higher earners pay a greater share (Taylor 2010, 6).

This paper seeks to determine equitable policy implications for the congestion problem in America's cities. To accomplish this, a flat tax rate on ride-hailing will be compared to various road pricing mechanisms including area-based charging and service tolls using the previously mentioned equity indicators. This paper will unfold in four sections: a brief overview of ridehailing in the United States and the congestion problem that it poses for cities, a review of the literature around congestion and equity, a description and assessment of equity between a flat tax rate and road pricing mechanisms, and broad implications resourced from the literature for future policy.

\section{OVERVIEW}

Ride-hailing allows companies to pair passengers with drivers using mobile applications without passengers necessarily having to share a ride with someone else. This is in contrast to ride-sharing where commuters can split the cost of a shared ride that makes multiple stops. The most common ride-hailing companies today are Lyft and Uber. Despite these benefits, ridehailing has introduced new issues, particularly for America's cities (Clewlow \& Mishra 2017). Among these is an increased level of traffic congestion, where the US leads with the most cities at the top of the Global Congestion Ranking (INRIX 2018). Several governments around the world have introduced legislation to combat these negative externalities (INRIX 2018). 
Ride-hailing is not a new concept. During World War II, the United States mandated that certain workplaces with inadequate transportation provide ride-hailing arrangements. Today, we know ride-hailing as a revolution in the transportation sector that was made possible by a combination of contemporary technologies such as the Global Positioning System (GPS), electronic fund transfers, and the smartphone. Even as early as the beginning of the 1990s, researchers imagined an advanced future for the US in terms of transportation--one that looks similar to what we have today (Hahn \& Metcalfe 2017).

Since Uber debuted in 2009, the ride-hailing industry has experienced tremendous growth. Today, 36 percent of adults in the United States say that they have used a ride-hailing service compared to just 15 percent back in 2015. The industry has become increasingly popular among higher educated and younger age groups. For example, individuals with at least a bachelor's degree are more than twice as likely (55 percent) to have used ride-hailing when compared to people who had at least a high school diploma or less (20 percent). Additionally, nearly twice as many people use ride-hailing services in urban areas compared to rural areas. One explanation for this large gap could be that the low population density of rural areas combined with longer travel distances discourages drivers to work in these areas (Jiang 2019).

Today, fewer Americans in major cities are driving and/or using their transit systems because of ride-hailing services. Results from a 2017 survey conducted by the University of California-Davis Institute of Transportation Studies showed a 6 percent reduction in the number of individuals that use bussing systems and a 3 percent reduction in light rail services. Twenty-one percent of adults used ride-hailing services with 24 percent of this group using the services regularly. There are several reasons why people may want to switch to ride-hailing. Survey respondents identified parking as the top reason that urban ride-hailing users avoid driving. Thirty-three percent of respondents said they use ride-hailing services rather than taking the metro or driving because they have been drinking. Further, more than half of all respondents that have used ride-sharing have discontinued the service--23 percent say they did so because they use ride-hailing (Clewlow \& Mishra 2017).

Ride-hailing, along with other technology, plays a key role in making tourism easier. Today, one can book a ride with Uber or Lyft before they arrive at their destination. Previous research indicates that high tourism demand can produce both negative and positive externalities. On one side, highly toured areas may make residents better off by boosting the local economy. However, tourism has historically increased traffic congestion among cities. When these negative consequences are not taken into consideration, tourism in the area may become unsustainable (Biagi, Brandono, and Detotto 2012).

In 2019, researchers from the University of Kentucky collaborated with researchers from the San Francisco County Transportation Authority to give ride-hailing "by far the most detailed look that's been done in any given city." Researchers analyzed San Francisco's traffic congestion for two six-week periods: one in 2010 and a similar period in 2016, years after the ride-hailing industry came to dominate the US transportation sector. The results of the study showed a 60 percent increase in San Francisco's everyday traffic in just six years. Over half of the surge in traffic was due to just two companies: Uber and Lyft. The model the researchers developed shows that without the presence of the two companies, traffic congestion would 
have only increased by 22 percent (Kennedy 2019). The findings produced by this study go against the Uber and Lyft's claims about the impact of their services on cities. Both companies responded by emphasizing the efficiency of their ride-sharing products in reaching a more equitable solution for all riders. However, researchers rebutted with the fact that most people do not share their rides with others (Kennedy 2019).

The rise of ride-hailing has started a debate in cities around the world that asks, "how do cities handle congestion equitably?" In Washington, DC, many residents and government officials say the flat tax rate on all ride-hailing activities makes life more difficult for lowerincome individuals (Siddiqui 2018b). This echoes the academic literature on congestion pricing that says, "since congestion pricing imposes a cost on something that was previously free--access to roadways during peak driving times--critics often suggest that it will harm those with lower incomes who will be forced to pay additional costs or be priced off of the roads" (Ecola and Light 2009, ix). It is difficult to discern the most equitable option to reduce congestion in cities such as DC. However, studies on road pricing initiatives in London, Singapore, and Stockholm found that they provide a higher level of equity than a flat tax rate for all motorists. Notably, the road pricing mechanism in London provides congestion waivers to residents with disabilities and other disadvantaged groups who may need to reach cities for crucial services (Eliasson 2008; Leape 2006; Olszewski \& Xie 2005).

In a broad sense, equity is particularly concerned with the total cost and benefit directed toward different groups in society. However, specific concepts of equity can have a large degree of variation. The literature outlines several indicators that can be used to evaluate equity in congestion pricing methods (Maruyama \& Sumalee 2007). This paper will use the following criteria sourced from the literature to assess equity among a flat tax rate system and various road pricing mechanisms: transportation access and vertical equity. Looking at accessibility will allow us to focus on actual outcomes rather than outputs such as spending, while assessing vertical equity will allow us to determine how each congestion mechanism affects members of different groups relative to one another. This analysis will uncover equitable policy implications for the traffic congestion problem by comparing a flat tax rate on ride-hailing to various road pricing mechanisms.

\section{FLAT TAX RATE}

The surge in popularity of ride-hailing services such as Uber and Lyft have caused policymakers in several major US cities to consider ways to reduce congestion in highly traveled areas. One of these methods is known as a flat tax rate on ride-hailing. This is a system where consumers pay a fixed rate for using services that contribute to congestion (Adu et al. 2018). For example, Washington, DC recently raised its flat tax rate on ride-hailing services from 1 percent to 6 percent. People using Uber or Lyft went from paying $\$ 0.20$ to $\$ 1.20$ in taxes for a $\$ 20$ ride (Cioffi, Segraves, and Swalec 2018). DC government officials explained that these charges were meant for the suppliers of the rides, but both companies said the tax would be passed onto consumers (Siddiqui 2018a). This is supported by previous literature that indicates consumers bear more burden of sales tax in general (Alm, Sennoga, and Skidmore 2009). 
Those who support a tax on these services say they help the community by raising funds for crucial infrastructure projects such as increased highway and road systems. In DC, the recent sales tax hike on ride-hailing is projected to generate between \$23 and \$25 million annually to find the Metro system" (Cioff, Segraves, and Swalec 2018). However, critics argue that a flat tax rate on these services does not address inequities in transportation among residents in low-income neighborhoods (Adams 2018). One study noted that increasing the amount of infrastructure, a common goal for flat tax rate revenue, reduces the ability to travel for some by inducing demand and bringing more vehicles to the area (Hamilton 2018). Unlike congestion pricing, there is very little literature on a flat tax rate's effect on the speed and accessibility of transit options such as a rail system (Milam et al. 2017).

The literature shows that a flat tax rate on ride-hailing services would decrease the vertical equity, or the idea that all groups of people are treated the same (Maruyama \& Sumalee 2007). As previously mentioned, ride-hailing allows companies to pair passengers with drivers without necessarily having to share a ride with someone else. Ride-sharing allows commuters to split the cost of a shared ride that makes multiple stops. A dissertation from the University of California Los Angeles Institute for Transportation Studies found a strong association between low rates of vehicle ownership and Lyft usage. Further, the study showed that a higher proportion of low-income individuals used ride-sharing than any other group (Brown 2018). Washington DC's flat tax rate makes no distinction between ride-hailing and ride-sharing. This means that people who want to take their own Uber can do so at the same rate as others who split the cost of a shared ride with someone else. In comparison, the City of New York will soon implement a congestion pricing strategy that will distinguish between ride-hailing and ride-sharing (Wamsley 2019). Those who share a ride would be expected to pay a $\$ 0.75$ surcharge per rider while those who do not share a ride would pay $\$ 2.75$ to enter highly congested areas ( $\mathrm{Hu} 2019)$. A flat tax rate not only discourages ride-sharing but unfairly targets disadvantaged groups while benefitting non-disadvantaged groups who share a lower burden of the tax. Washington DC's flat tax rate, when compared to other cities with similar models, is one of the most radical examples (Siddiqui 2018b). Unlike various congestion pricing models, the literature on flat tax rates does not suggest that a model exists that provides any sort of waiver for disadvantaged groups similar to London's congestion waiver for residents with disabilities.

\section{ROAD PRICING}

Road pricing is another approach that can reduce traffic congestion in cities. Here, motorists are charged a direct fee for using a certain route in a particular area. These charges are not meant to target any one group but can be used to discourage certain vehicles such as large semi-trucks from constant usage of certain routes. Most governments that use road pricing to reduce congestion rely on toll checkpoints such as bridges and tunnels to implement road pricing. Currently, this type of congestion pricing is limited to a few notable cities and urban roads including Singapore and Stockholm. According to the literature, there are two goals in particular that guide road pricing decisions: congestion management and revenue generation (Rouhani 2016). This paper considers service tolls and area-based charging.

One example of road-pricing is service tolls. Here, the primary objective is to build revenue rather than reducing congestion. Tolls are typically used to generate funds to cover 
expenses related to infrastructure needs such as maintenance. Tolls are typically administered at bridges, tunnels, and other unique infrastructure checkpoints. In the United States, tolls are more common than area-based charging systems. However, most research says that because the primary focus of tolls is to generate revenue, most tolls usually end up decreasing "transportation system performance because of traffic spillovers to other parts of the system and to lower travel demand (which itself represents a decrease in social welfare)" (Rouhani 2016, 5).

When implementing road pricing, policy makers and other government officials may want to generate revenue for infrastructure improvements even for uncongested areas. One example is the turnpike system in Oklahoma, where the state charges drivers a toll for using roads that need maintenance. The Oklahoma Turnpike Authority generated \$317.7 million in 2018 to cover costs such as operation and maintenance (Oklahoma Turnpike Authority 2019, 6). Counter to what social welfare policy would employ, revenue generation typically sets prices and toll rates high to create a large profit (total revenue - total cost). In other situations, policy makers and other government officials may want to use road pricing to reduce congestion. Here, prices are strategically set to minimize certain indicators of road congestion, such as high rush hour traffic, and incentivize consumers to use their metro and transit options instead. Since this method charges high prices during periods of high congestion rather than at any given time throughout the day, the revenue generated is typically used for developments beyond maintaining infrastructure and transportation services (Taylor 2010). The following points detail specific ways in which governments have implemented road pricing systems.

Several governments have implemented what is known as an area-based charging system. This charges consumers for a permit to enter and travel in a specified area for a certain amount of time. After the initial charge, motorists are not required to pay any additional fees. The basic assumption of this method of road pricing is that motorists should be responsible for any negative externalities they discharge. As congestion becomes a more serious issue for America's cities, consumers' usage of services that contribute to said congestion, such as ridehailing services, slow down their travels. The overarching idea is to "charge users for their social costs (the congestion-related difference between marginal social cost and marginal private cost) to use roads more efficiently" (Vickrey 1963; Walters 1970).

Both London, United Kingdom and Stockholm, Sweden have developed area-based charging systems. In London, the congestion charge is $£ 11.50$ for driving a licensed vehicle in specific, highly congested areas of the city from Monday to Friday between 07:00 and 18:00 (BBC 2014). One study showed that the London area-based charging system lacked the optimal congestion pricing for road usage (Ecola and Light 2009). Studies on Stockholm's areabased congestion pricing also indicated unpredicted and excessive costs when the optimal pricing was not set (Eliasson 2008). Nevertheless, it would be possible to create a similar system such as Stockholm's for a much lower price by modifying the cost of applied insurance and informing the public about costs and benefits (Hamilton 2011). A study on time-variable road pricing, which increases the charge before peak hours and decreases afterward, found that this mechanism "transfers congestion to other periods and other routes and is an effective method of controlling congestion” (Olszewski \& Xie 2005).

Research suggests that road-pricing mechanisms are more beneficial than a flat tax rate system when it comes to transportation access. A collection of studies on London's congestion 
pricing system show positive results for disadvantaged residents (Ecola and Light 2009). For example, one highlighted that people with disabilities in the area reported no change in their travel schedules due to the congestion pricing. This results from a provision within London's road pricing system that allows certain disadvantaged groups to apply for congestion waivers. This idea holds true for the road pricing system in Stockholm, Sweden. Similar to a flat tax rate, funds derived from these projects finance the transit systems that improve transportation access for low-income individuals and the general public. Congestion pricing has also been shown to increase the speed of public transit options such as buses and ride-sharing, which ultimately makes transit systems more affordable (US Department of Transportation 2009, 8). Further, these mechanisms should not disincentivize ride-sharing like a flat tax rate would.

Road pricing mechanisms still affect vertical equity. A flat tax rate has received a lot of attention from critics who say that the concept is unfair to lower-income individuals. These issues are less common in the road pricing literature but are still prevalent and worth mentioning. Even though London's system contains provisions to remove the congestion pricing for disadvantaged groups, this does not mean that all members of disadvantaged groups will receive a waiver. In a recent report on London's system, 50 percent of low-income households reported congestion tolls as unfair compared to 30 percent of individuals who were not low-income. However, the rates at which these two groups changed their travel were strikingly similar: 70 percent for low-income households and 60 percent for those who are not low-income (Ecola and Light 2009, 19). In the long run, however, congestion pricing would fund more car-free alternatives for all without disincentivizing carpooling (Dzintars and Sutton, n.d). Road pricing, like a flat tax rate, leaves some groups at risk, but its features appear to have a better future in store for motorists.

\section{POLICY IMPLICATIONS}

After considering consumer's transportation access and vertical equity, it is clear that road-pricing would be more equitable than a flat tax rate in reducing traffic congestion. This mechanism, unlike a flat tax rate, would charge individuals differently based on whether they decide to enter congested areas alone or in a shared ride. These cheaper alternatives are crucial for some individuals/motorists/residents. When implemented with concern for equity, roadpricing mechanisms can reduce congestion pricing's burden on disadvantaged groups. These policies could also lead to "more frequent and affordable public transit, safer pedestrian and bicycle routes - all important components of an equitable transportation system" (Cohen and Hoffman 2019). Further, there are several conclusions drawn from the literature on equitybased policy solutions for traffic congestion for future policy:

- Policy makers should consider congestion waivers to serve disadvantaged groups when implementing any sort of congestion pricing. Again, London provides this as an option for people with disabilities who may need to reach cities for crucial services.

- Policy makers should direct the revenue generated from any attempt at curbing congestion toward transit systems that would benefit disadvantaged groups if they were easier to access. 
- Depending on the city, some may want to implement discounted alternatives that would help to ensure transportation access and vertical equity to disadvantaged groups.

- Determine optimal pricing to avoid unpredicted and excessive costs.

- Policy makers should pay attention to externalities caused by tourists. The impact of these externalities, whether negative or positive, are important to understand when implementing congestion strategies (Biagi, Brandono, and Detotto 2012).

\section{CONCLUSION}

Over the last decade in the United States, the ride-hailing industry has experienced tremendous growth. In just ten years, the technology has expanded-with most Americans having used this service before. Despite the relative ease ride-hailing offers, data show alarming rates of increased congestion in America's cities. Comparing different methods of congestion pricing using specific equity indicators to derive meaningful findings from the literature provides a useful framework for analyzing congestion. While a number of papers have been published in this area, further research is needed to fully determine the most equitable option when considering congestion pricing. Policy makers should consider the tradeoffs between different congestion pricing mechanisms moving forward. Further, officials should always strive to ensure that these systems work for everyone by searching for ways in which to maximize equity.

\section{REFERENCES}

Adu, Paa, Stella Chen, Gonzalo Pozo, and Stephen Zoepf. 2018. The Economics of Ride Hailing: Driver Revenue Expenses and Taxes. Cambridge: Massachusetts Institute of Technology Center for Energy and Environmental Policy Research. https://orfe.princeton.edu/ alaink/SmartDrivingCars/PDFs/Zoepf_ The\%20Economics\%20of\%20RideHialing_OriginalPdfFeb2018.pdf.

Adams, Sam. 2018. "Don’t Enact a 'Lazy' Ride-Hailing Tax." City Lab, July 25, 2018. https://www.citylab. com/perspective/2018/07/dont-enact-a-lazy-ride-hailing-tax/563825/.

Alm, James, Edward Sennoga, and Mark Skidmore. 2009. Perfect Competition, Urbanization, and Tax Incidence in the Retail Gasoline Market. Economic Inquiry. https://www.researchgate.net/ publication/23960980_Perfect_competition_urbanization_and_tax_incidence_in_the_retail_ gasoline_market/link/5c49ca68299bf12be3e05aca/download

BBC. 2014. London's Congestion Charge Rises to $£ 11.50$. London: BBC, June 16, 2014. https://www.bbc.com/ news/uk-england-london-27865252

Biagi, Bianca, Maria Giovanna Brandano, and Claudio Detotto. 2012. "The Effect of Tourism on Crime in Italy: A Dynamic Panel Approach.” Economics: The Open-Access, Open-Assessment E-Journal, 6 (July): 1-24. http://dx.doi.org/10.5018/economics-ejournal.ja.2012-25.

Brown, Anne. 2018. "Ridehail Revolution: Ridehail Travel and Equity in Los Angeles." PhD diss., University of California, Los Angeles. https://www.its.ucla.edu/2018/06/27/ridehail-revolution-groundbreakingits-dissertation-examines-discrimination-and-travel-patterns-for-lyft-uber-and-taxis/. 


\section{Equity Among Policy Solutions for Traffic Congestion}

Cioffi, Chris, Mark Segraves, and Andrea Swalec. 2018. DC Council Approves Tax Hike on Uber, Lyft Rides to Fund Metro. Washington: NBC. https://www.nbcwashington.com/news/local/dc-councilapproves-tax-hike-on-uber-lyft-rides-to-fund-metro/2056008/

Clewlow, Regina and Gouri Mishra. 2017. Disruptive Transportation: The Adoption, Utilization, and Impacts of Ride-Hailing in the United States. Davis: University of California, Davis Institute of Transportation Studies. http://usa.streetsblog.org/wp-content/uploads/sites/5/2017/10/2017_ UCD-ITS-RR-17-07.pdf.

Cohen, Stuart and Alan Hoffman. 2019. Pricing Roads, Advancing Equity. Oakland: TransForm. https:// www.transformca.org/sites/default/files/Pricing_Roads_Advancing_Equity_Combined_ FINAL_190128_0.pdf.

Dzintars, Aleks and Tyler Sutton. n.d. An Analysis of Traffic Congestion and Policy Solutions for Canadian Municipalities. London: Public Sector Digest. https://publicsectordigest.com/sites/default/files/ PSD_STUDY-Traffic_and_Congestion.pdf.

Ecola, Liisa and Thomas Light. 2009. Equity and Congestion Pricing: A Review of the Evidence. Santa Monica: RAND Corporation. https://www.rand.org/pubs/technical_reports/TR680.html.

Eliasson, Jonas. 2008. "Lessons from the Stockholm Congestion Charging Trial." Transport Policy Volume 15, Issue 6 (November): 395-404. https://doi.org/10.1016/j.tranpol.2008.12.004.

Hahn, Robert and Robert Metcalfe. 2017. The Ride-sharing Revolution: Economic Survey and Synthesis. Washington: Brookings. https://www.brookings.edu/wp-content/uploads/2017/01/ride-sharingoup-1117-v6-brookings1.pdf.

Hamilton, Carl. 2011. "Revisiting the Cost of the Stockholm Congestion Charging System. Transport Policy Volume 18, Issue 6 (November): 836-847. https://doi.org/10.1016/j.tranpol.2011.05.004.

Hamilton, Eric. 2018. "Study Calls for Curbing Congestion by Building Fewer Roads." Phys.org, November 29, 2018. https://phys.org/news/2018-11-curbing-congestion-roads.html.

Hu, Winnie. 2019. "Your Taxi or Uber Ride in Manhattan Will Soon Cost More." New York Times, January 31, 2019. https://www.nytimes.com/2019/01/31/nyregion/uber-taxi-lyft-fee.html.

INRIX. 2018. Los Angeles Tops INRIX Global Congestion Ranking. Kirkland: INRIX, February 5, 2018. http:// inrix.com/press-releases/scorecard-2017/.

Jiang, Jingjing. 2019. More Americans are Using Ride-Hailing Apps. Washington: Pew Research Center. https://www.pewresearch.org/fact-tank/2019/01/04/more-americans-are-using-ride-hailing-apps/.

Kennedy, Merrit. 2019. "Uber and Lyft Caused Major Traffic Uptick in San Francisco, Study Says." NPR, May 8, 2019. https://www.npr.org/2019/05/08/721139488/uber-and-lyft-caused-major-traffic-uptickin-san-francisco-study-says.

Leape, Jonathan. 2006. “The London Congestion Charge." The Journal of Economic Perspectives Vol. 20, No. 4 (Fall 2006): 157-176. https://www.aeaweb.org/articles?id=10.1257/jep.20.4.157.

Maruyama, Takuya and Agachai Sumalee. 2007. "Efficiency and Equity Comparison of Cordon and Area Based Road Pricing Schemes Using a Trip-Chain Equilibrium Model." Transportation Research Part A: Policy and Practice Vol. 41, Issue 7 (August): 655-671. https://doi.org/10.1016/j. tra.2006.06.002.

McCahill, Chris and Mary Ebeling. 2015. "Tools for Measuring Accessibility in an Equity Framework." Paper presented at the Congress for the New Urbanism 23rd Annual Meeting. Dallas, TX, April $29-$ May 2, 2015. https://www.cnu.org/sites/default/files/ssti_transpo_equity.pdf.

Milam, Ronald T., Marc Birnbaum, Chris Ganson, Susan Handy, and Jerry Walters. 2017. "Closing the Induced Vehicle Travel Gap Between Research and Practice." Transportation Research Record 2653, no. 1 (January): 10-16. https://doi.org/10.3141/2653-02. 


\section{Featured Articles}

Oklahoma Turnpike Authority. 2019. Comprehensive Annual Financial Report 2018. Oklahoma City: Oklahoma Turnpike Authority. https://www.pikepass.com/pdf/OTA\%20CAFR\%202018.pdf.

Olszewski, Piotr \& Litian Xie. 2005. "Modeling the Effects of Road Pricing on Traffic in Singapore." Transportation Research Part A: Policy and Practice Vol. 39, Issue 7-9 (August-November): 755 772. https://doi.org/10.1016/j.tra.2005.02.015.

Rouhani, Omid. 2016. "Next Generations of Road Pricing: Social Welfare Enhancing." Sustainability 8(3), (March): 265. https://doi.org/10.3390/su8030265.

Schaller, Brian. 2018. The New Automobility: Lyft, Uber and the Future of American Cities. New York: Schaller Consulting. http://www.schallerconsult.com/rideservices/automobility.pdf.

Siddiqui, Faiz. 2018a. “D.C. Council's Vote to Increase Ride-Hailing Tax Will Probably Mean Higher Uber and Lyft Fares - to Support Metro.” Washington Post, June 26, 2018. https://www.washingtonpost. com/news/dr-gridlock/wp/2018/06/26/d-c-councils-vote-to-increase-ride-hailing-tax-will-likelymean-higher-uber-and-lyft-fares-to-support-metro/?utm_term=.6782e6ad604a.

---. 2018b. "Why D.C. is Targeting the Ride-Hail Industry." Washington Post, June 26, 2018. https:// www.washingtonpost.com/local/trafficandcommuting/why-dc-is-targeting-the-ridehail-industry/2018/03/31/ef01fca8-3473-11e8-94fa-32d48460b955_story.html?utm_ term $=.073 \mathrm{~d} 54 \mathrm{f} 2 \mathrm{fae} 3$.

Suzor, Nicolas, Patrik Wikström, and Alice Witt. 2015. "Regulating Ride-Sharing in the Peer Economy." Communication Research and Practice Vol. 1, Issue 2 (June): 174-190. https://doi.org/10.1080/2204 1451.2015.1048041.

Taylor, Brian. 2010. How Fair is Road Pricing? Evaluating Equity in Transportation Pricing and Finance. Washington: Bipartisan Policy Center. https://bipartisanpolicy.org/wp-content/uploads/sites/ default/files/BPC\%20Pricing\%20EquityFIN.pdf.

United States Department of Transportation Federal Highway Administration. 2006. Transit and Congestion Pricing: A Primer. Washington: US Department of Transportation. https://ops.fhwa.dot.gov/ publications/fhwahop09015/fhwahop09015.pdf.

Vickrey, William. 1963. "Pricing in Urban and Suburban Transport." American Economic Association Vol. 53, No. 2 (May): 452-465. https://www-jstor-org.proxygw.wrlc.org/stable/pdf/1823886.pdf?ab_ segments=0\%2Fbasic_SYC-4946\%2Fcontrol\&refreqid=search\%3Affcecd2e41825427dc69315559d $3 \mathrm{e} 6 \mathrm{~b} 3$.

Walters, Alan. 1970. “The Economics of Road User Charges.” Journal of Economic Literature Vol. 8, No. 1 (March): 99-100. https://www-jstor-org.proxygw.wrlc.org/stable/pdf/2720422.pdf?ab_ segments=0\%2Fbasic_SYC-4946\%2Fcontrol\&refreqid=search\%3Ac92b904de57505c08af74f104a4 $806 \mathrm{bb}$.

Wamsley, Laurel. 2019. "New York Is Set To Be First U.S. City To Impose Congestion Pricing.” NPR, April 2, 2019. https://www.npr.org/2019/04/02/709243878/new-york-is-set-to-be-first-u-s-city-to-imposecongestion-pricing. 
ETHAN STEAKLEY is a second-year Master of Public Policy candidate

focusing on urban policy and program evaluation. He graduated with a BA in political science and BS in psychology from the University of Science and Arts of Oklahoma. Ethan currently works as a Graduate Intern in the Applied Research department of a nonprofit called Prosperity Now where he assists with research related to asset-building, debt management and innovation. In his free time, he enjoys going to the library, taking his dog for long walks, and traveling to new places.

\section{ACKNOWLEDGEMENTS}

The author would like to thank Dr. Anil Nathan, whose economics course inspired this paper. He also thanks Managing Editor Jackie Wheeler, Associate Editor Thomas Rachko, and his faculty reviewer, Dr. Kate Yang for their wonderful feedback and guidance. This would not have been possible without their thoughtful recommendations. Finally, he thanks the Trachtenberg School for providing the opportunity to contribute to Policy Perspectives in this capacity. 